\title{
Block technology of speed and strength training of technical university students in cross-country athletics
}

\author{
Anatoly Zyukin ${ }^{1}$, Ildus Gibadullin ${ }^{2 *}$, Oksana Kovalchuk ${ }^{3}$, Talgat Sagiev $^{3}$, Lyudmila Shelkova $^{1}$ \\ ${ }^{1}$ Russian State Pedagogical University named after A.I. Herzen, 191186, Saint Petersburg, Russia \\ ${ }^{2}$ Izhevsk State Technical University named after M. T. Kalashnikov, 426069, Izhevsk, Russia \\ ${ }^{1}$ Omsk State Technical University, 644050, Omsk, Russia
}

\begin{abstract}
This article deals with the problem of speed and power training of Omsk state technical University students in athletics classes during the academic year, taking into account their individual initial level of speed and power motor abilities development. The article describes the preparatory, forming and implementation blocks of the author's developed block technology for building academic classes in cross-country athletics, shows the focus of classes on the development of specific modules. This study also involves testing the effectiveness of the developed block technology in the course of a pedagogical experiment. The author's technology provides a two-cycle structure, that is, it covers academic classes of the first and second semesters. Significant differences in the planning of the experimental method classes consist in the development of lagging individual aspects of the student's training, thereby selectively affecting and concentrating the development of speed-power, power and speed parameters of muscle work in running in separate classes. Moreover, the training tools in the forming and implementing blocks EG1, EG2 and CG do not differ, only the content of exercises changes by applying various pedagogical methods of regulating physical activity (changing the amount of burden, duration of work, rest, intensity, mode, character of muscle contraction). The results of research can be used in the educational process with schoolchildren, students of universities, colleges.
\end{abstract}

\section{Introduction}

The organization of the modern educational process in athletics in a non-core university needs new technological solutions aimed at the harmonious development of various aspects of students physical fitness throughout the training period, the formation of performance, skills and abilities suitable for future professional activities [1, 2]. However, if we take into account that at present the level of first-and senior-year students physical fitness is rapidly decreasing and is rated as "low" and "below average" [3,4,5,6]. This suggests that traditional physical training is ineffective. The traditional method does not take into account an individual approach to the development of the leading speed and power qualities of a runner, namely, the initial level of explosive starting power, speed endurance individual parameters development in conditions of submaximal intensity, speed and power endurance in submaximal and maximum intensity.

Purpose - to determine the effectiveness of the developed block technology of speed and strength training of university students in academic athletics classes, taking into account individual typological features of the development of speed and strength qualities.

\section{Materials and methods}

The following research methods were used: analysis and generalization of scientific and methodological literature, pedagogical observation, pedagogical testing, pedagogical experiment, methods of mathematical statistics.

The research was conducted at the Omsk state technical university (OmGTU). The pedagogical experiment was organized from September 2019 to May 2020, 75 first-year boys specializing in cross-country athletics took part.

\section{Results and discussion}

As a result of our pedagogical observations, it was found that during the academic year, the aerobic nature of work prevails, where the same type of general and special running exercises are used, the nature and direction of which does not change throughout the academic year. This contradicts the opinions of researchers. They argue that for the

\footnotetext{
* Corresponding author: ffkis@istu.ru
} 
growth of results in running sports, it is important to pay systematic attention to muscle strength and the speed of its growth, so a variety of speed and strength exercises should form the basis of the pedagogical process $[2,3,5,6]$.

In this regard, we have proposed a pedagogical technology that is implemented in two cycles of annual training. It is represented by the following blocks: preparatory, formative, and implementation. Each block included modules that emphasized developing lagging components in preparedness.

In order to test the effectiveness of the developed block technology for the development of speed and strength qualities in track and field students, we conducted a pedagogical experiment. 25 athletes made up the experimental group №1 (hereinafter EG1). It was characterized by a low level of speed endurance development (having reduced performance in middle-and long-distance running). Experimental group № 2 (hereinafter EG2) consisted of 25 athletes with a low level of explosive strength and speed-strength qualities (reduced performance in tests of sprint running). The control group consisted of 25 athletes who are engaged in traditional methods and have averaged performance in running short and medium distances. In the EG1 and the EG2, classes were conducted using the technology developed by us for block training of track and field athletes, taking into account individual typological features of speed and strength qualities development.

The preparatory block in the EG1 and the EG2 did not differ. It solved the problems of increasing the functional capabilities of the cardiovascular system, General endurance, strengthening all muscle groups, and the musculoskeletal system with the help of isometric and statodynamic exercises. This block covered 5 microcycles. They mainly developed 2 modules-general aerobic endurance and General power statodynamic endurance.

At the stage of the forming block in EG1 and EG2, most of the load was directed to the accentuated development of the preparedness weaknesses. In EG1-development of absolute and explosive strength, power anaerobic endurance. The work involved special and general strength and running exercises with weights (projectiles). In EG2, students performed long-term strength and running work of general and special orientation with little or no weight. At the end of each approach in the exercise, heart rate indicators reached the lower limit of submaximal intensity.

The implementation block in EG1 assumed running work to increase special speed and power endurance in the maximum and submaximal modes of muscle activity energy supply with the use of power anaerobic exercises of a general orientation. In EG2, the block was focused on increasing special speed endurance in running in submaximal conditions of energy supply additionally, anaerobic strength exercises of general orientation were used for all muscle groups.

In order to determine the dynamics of the studied indicators, we conducted a control test before the experiment (at the beginning of the academic year) and after the experiment (at the end of the academic year) (table 1).

Table 1. Indicators of first-year runners physical fitness in the control and experimental groups before and after the pedagogical experiment, $(\mathrm{M} \pm \sigma)$

\begin{tabular}{|c|c|c|c|c|c|c|c|c|c|c|c|c|}
\hline \multirow[t]{2}{*}{ Tests } & \multicolumn{4}{|c|}{ EG1, $(n=25)$} & \multicolumn{4}{|c|}{ EG2, $(n=25)$} & \multicolumn{4}{|c|}{$\mathrm{CG},(\mathrm{n}=25)$} \\
\hline & $\begin{array}{c}\text { before the } \\
\text { experime } \\
\text { nt }\end{array}$ & $\begin{array}{c}\text { after the } \\
\text { experime } \\
\text { nt }\end{array}$ & $\mathrm{P}$ & $\begin{array}{c}\mathrm{Z}, \\
(\%)\end{array}$ & $\begin{array}{c}\text { before the } \\
\text { experime } \\
n t\end{array}$ & $\begin{array}{c}\text { after the } \\
\text { experime } \\
\text { nt }\end{array}$ & $P$ & $\begin{array}{l}\mathrm{Z} \\
(\%)\end{array}$ & $\begin{array}{l}\text { before } \\
\text { the } \\
\text { experim } \\
\text { ent }\end{array}$ & $\begin{array}{c}\text { after the } \\
\text { experime } \\
\text { nt }\end{array}$ & $\mathrm{P}$ & $\begin{array}{c}\mathrm{Z}, \\
(\%)\end{array}$ \\
\hline $\begin{array}{l}\text { Running } 100 \\
\mathrm{~m},(\mathrm{sec})\end{array}$ & $13,6 \pm 0,6$ & $13,2 \pm 0,5$ & $*$ & 3 & $14,7 \pm 0,9$ & $13,7 \pm 0,8$ & $*$ & 7 & $14,3 \pm 1,0$ & $14,1 \pm 0,9$ & - & 1 \\
\hline $\begin{array}{l}\text { Running } \\
3000 \quad \mathrm{~m} \text {, } \\
(\mathrm{sec})\end{array}$ & $816 \pm 55$ & $697 \pm 41$ & $*$ & 15 & $753 \pm 31$ & $702 \pm 34$ & $*$ & 7 & $776 \pm 39$ & $727 \pm 33$ & $*$ & 6 \\
\hline $\begin{array}{l}\text { Pull ups, } \\
\text { (number of } \\
\text { times) }\end{array}$ & $9 \pm 2,2$ & $11 \pm 2,1$ & $*$ & 22 & $6 \pm 2,1$ & $10 \pm 1,9$ & $*$ & 67 & $7 \pm 2,1$ & $8 \pm 1,7$ & - & 14 \\
\hline $\begin{array}{l}\text { long jump } \\
\text { from a place, } \\
(\mathrm{cm})\end{array}$ & $241 \pm 19$ & $253 \pm 14$ & $*$ & 5 & $224 \pm 15$ & $248 \pm 18$ & $*$ & 11 & $234 \pm 20$ & $239 \pm 21$ & - & 2 \\
\hline $\begin{array}{l}\text { Running } 60 \\
\mathrm{M},(\mathrm{sec})\end{array}$ & $8,0 \pm 0,3$ & $7,7 \pm 0,3$ & $*$ & 4 & $8,4 \pm 0,4$ & $7,9 \pm 0,4$ & $*$ & 6 & $8,2 \pm 0,6$ & $8,1 \pm 0,5$ & - & 1 \\
\hline $\begin{array}{l}\text { Running } 200 \\
\mathrm{~m},(\mathrm{sec})\end{array}$ & $27,9 \pm 1,0$ & $26,0 \pm 1,1$ & $*$ & 7 & $30,7 \pm 1,4$ & $27,0 \pm 1,4$ & $*$ & 12 & $29,0 \pm 3,3$ & $28,1 \pm 2,8$ & - & 3 \\
\hline $\begin{array}{l}\text { Running } 400 \\
\mathrm{~m},(\mathrm{sec})\end{array}$ & $63,6 \pm 3,3$ & $59,6 \pm 3,5$ & - & 6 & $64,9 \pm 3,5$ & $58,8 \pm 4,0$ & - & 9 & $65,5 \pm 3,6$ & $63,8 \pm 4,3$ & - & 1 \\
\hline
\end{tabular}

Note: * - confidence of differences at $\mathrm{P}<0,05$;

(Z) - increase in $(\%)$.

Table 1 shows that EG1 and EG2 athletes have significant changes in all the studied indicators. For CG representatives, changes with significant significance are observed only in the $3000 \mathrm{~m}$ run (an increase of $6 \%$ ).

In EG2 track and field athletes, where the work was aimed at improving sprinting qualities, power and speedpower indicators increased 2-3 times than in EG1 athletes, as well as in short-distance running $60 \mathrm{~m}$ and $100 \mathrm{~m}$, the 
increase was 6-7\%, which is 2 times higher than the increase in EG1 athletes. However, it should be noted that the EG1 athletes (who in the course of the experiment focused on increasing the adaptive responses of the body in middle-distance running) in the test "running 3000m". It increased by $15 \%$, although in the EG2 athletes this indicator is only $7 \%$.

\section{Conclusions}

The evidence of the block technology effectiveness developed by us for training university students in athletics classes, taking into account the level of speed and strength qualities development, is the largest increase in indicators in pedagogical tests with reliable significance for representatives of EG compared to CG. However, it should be noted that the athletes of both experimental groups have the most significant increase in indicators observed in pedagogical tests that characterize certain parameters of speed and strength training, They are lagging in development, identified before the experiment. This, in turn, suggests the feasibility of selective pedagogical influence on the weaknesses of students speed and power motor abilities development by organizing the educational process of technical university students in the form of a block structure, within which the selective development of individual modules is carried out.

\section{References}

1. N. Poulos, S. Koutinen, M. Bucheit, The effect of preliminary squats on the sprint result in young athletes, IAAF athletics Bulletin, No. 3/4, (Volume 25), Pp. 95-103, (2010).

2. N.M. Prus, S.M. Uskova, Actual scientific research in the modern world, 1(45) part 5, 88-93 (2019)

3. E.N. Chernysheva, E.N. Karaseva, Scientific notes of the P.F. Lesgaft University, 2(168), 373-381 (2019)

4. T.A. Shilko, G.I. Golovko, E.V. Loson, Bulletin of Tomsk state University, 440, 190-194 (2019)

5. S. Loland, IAAF athletics Bulletin, 1(24), 90-91 (2009)

6. A.S. Kuznetsov, Z.M. Kuznetsova, Russian Journal of Physical Education and Sport, 14(4), 5-7 (2019) 